\title{
A Perspective on Covid-19, Dementia, and Intellectual Disabilities
}

\author{
Kathleen M Bishop* \\ University of Rochester, school of medicine and Dentistry (Retired), New York, USA
}

Submission: October 10, 2020; Published: December 15, 2020

*Corresponding author: Kathleen M Bishop, University of Rochester, school of medicine and Dentistry (Retired), New York, USA

\begin{abstract}
The impact of the COVID - 19 pandemics has affected the lives of billions of people around the world closing entire countries, isolating people from each other, and changing the day-to-day routines and habits. The US has been particularly hard hit economically, high loss of life, and the unknown lasting effects from the virus. Older adults have been particularly affected as the known risk factors such as cardiac disease, diabetes, and lung disease is more common in older adults [1].

Especially vulnerable group of people negatively affected by this disease has been older adults with intellectual disabilities (ID) and a diagnosis of Alzheimer's disease and Related Dementias. Their caregivers have also been challenged with attempting to provide health care supports, residential care, and activities of daily living during a time of so many unknowns and losses [2].
\end{abstract}

Keyword: Intellectual disabilities; Older adults; Habits; Alzheimer's disease; Residential care; Diagnosis

\section{Introduction}

Below is a very brief overview of some of those areas most affected by the disease and the resulting changes or challenges to daily support and advocacy:

\section{Diagnosis, healthcare support, and health care disparities}

For adults with ID and their caregivers, whether family, paid, or unpaid, providing informed and knowledgeable healthcare is always challenging especially when the older adult cannot communicate his/her symptoms. Health care providers are often unfamiliar or inexperienced with diagnosing dementia in adults with ID with pre-existing cognitive impairments and other preexisting conditions $[3,4]$.

Myths and stereotypes held by health care providers, especially for adults with Down syndrome who are known to have a higher risk for Alzheimer's disease compared to the general population, often assume decline from baseline functioning is normal to aging or should automatically be attributed to Alzheimer's disease thus not conducting a thorough diagnostic process [5].

Diagnosis or diagnostic follow-up during a pandemic with unknown symptoms or causes and people already at high risk for secondary conditions adds to the lack of aggressive assessments and interventions [3]. Tools to measure cognitive losses in adults with intellectual disabilities are limited and not available to many health care providers. Tests to diagnosis COVID - 19 in the US are still not always accurate or easily available compounding the problems with providing health care during a pandemic [3-6].

The already existing lack of health care infrastructure in many areas of the US and health care disparities have added to limited potential for health care during the pandemic. Treatments for age-related conditions such as cataract removal, hearing aides' adjustments, and pain management due to arthritis or osteoporosis were put on pause thus affecting the likelihood for increased discomfort and confusion for the adult with dementia [3-5].

For many communities and cities in the US, hospitals paused "elective health care" to be able to provide health care to those in serious or critical condition because of COVID-19. Very difficult discussions and decisions were and are still being made regarding how to prioritize who should receive care for the disease. Factors such as potential for future quality of life, likely longevity, chronological age, and degree of impairment from pre-existing conditions such as ID were all considered for availability of care. Pre-existing devaluing of persons with ID adds to the likelihood for less access to health care [3]. 


\section{Emotional stability and mental health concerns}

Each of us relies on habits and routines to function daily regardless of pre-existing disabilities or conditions. This makes it possible to interact with others, learn, conduct usual activities, and to feel less stressed because every movement does not have to be thought out in detail. COVID - 19 has changed every aspect of most people's lives including adults with ID and dementia when dementia had already added stress to feeling safe, emotionally stable, and comfortable [2].

In the US, most organizations supporting people with ID canceled daily programs or community activities, isolated small groups of people in group homes due to necessary state and local mandates, and limited social activity to family and residential peers. Even our language changed including phrases such as 'stay safe and healthy' becoming common goodbyes [2].

These changes created confusion for all of us, increasingly so for people with ID already stressed by the disease of Alzheimer's disease. For people in the general population the changes can be hard to understand, for people with significant cognitive decline it is even more challenging to understand with caregivers equally stressed or unable to explain [2].

\section{Socialization and Social Isolation}

COVID - 19 has created necessary social isolation. It is no longer safe to attend large group events or visit with family members or friends. Greetings such as shaking hands or hugging is now not safe, isolating people even more as the sense of touch is how we connect to our world and others around us. People with ID who have been taught the' socially correct' way to approach others now are told that this is unsafe. All of us struggle with this change but for people with ID and dementia at a time it is more difficult to learn new habits the fear and anxiety this causes is worse [2].

\section{Summary}

The global pandemic has stretched resources beyond their limit and reduced the capacity for advocacy for vulnerable populations, including adults with ID and dementia. But we all have the ability and most of us the desire to make a positive difference especially in times of health care crisis. By increasing awareness of the challenges and pre-existing health care disparities for older adults with ID and dementia we can make necessary changes for the future [2].

The changes and improvements we make for one group of vulnerable people can have a ripple effect, creating positive changes for many including adults in the general population. According to a Chinese proverb 'When you throw a pebble into the sea you can never know where the resulting wave will land.' Each of us can have a positive effect by considering the losses and throwing the first pebble into the sea to begin the process of positive change and healing.

The author hopes this very brief perspective will add to the readers awareness and the potential for future positive changes.

\section{References}

1. Janicki M, Pears K (2020) Introduction to COVID -19, Dementia, and IDD; Webinar series for the National Task Group on ID and Dementia Practices.

2. Bishop KM (2020) Social Distancing, Dementia, COVID - 19, and IDD; Webinar series for the National Task Group on ID and Dementia Practices.

3. Keller S (2020) The Healthcare Concerns of COVID-19 in People with IDD and Dementia; Webinar series for the National Task Group on ID and Dementia Practices.

4. Service K (2020) Keeping Healthy through COVID - 19 with Infection Control and More; Webinar series for the National Task Group on ID and Dementia Practices.

5. Bishop KM, Hogan M, Janicki MP, Keller SM, Lucchino R, et al. (2015) Guidelines for Dementia-Related Health Advocacy for Adults with Intellectual Disability and Dementia: National Task Group on Intellectual Disabilities and Dementia Practices. Intellectual and Developmental Disabilities 53(1): 2 -29.

6. National Task Group on Intellectual Disabilities and Dementia Practices (NTG). (2012a). 'My thinker's not working': A national strategy for enabling adults with intellectual disabilities affected by dementia to remain in their community and receive quality supports. Retrieved from www.aadmd.org/ntg/thinker.

\section{Your next submission with Juniper Publishers will reach you the below assets}

- Quality Editorial service

- Swift Peer Review

- Reprints availability

- E-prints Service

- Manuscript Podcast for convenient understanding

- Global attainment for your research

- Manuscript accessibility in different formats

( Pdf, E-pub, Full Text, Audio)

- Unceasing customer service

Track the below URL for one-step submission https://juniperpublishers.com/online-submission.php 